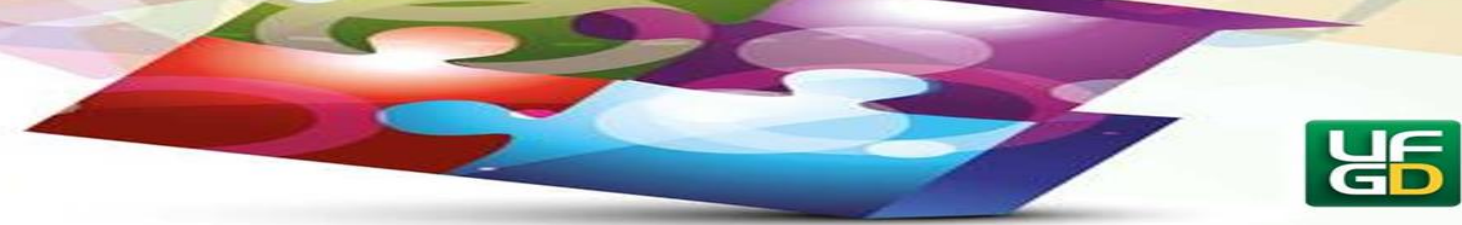

\title{
ESTRATÉGIAS DE ENFRENTAMENTO UTILIZADAS POR PESSOAS COM DEFICIÊNCIA E A IMPORTÂNCIA DE UMA REDE DE APOIO NO FORTALECIMENTO DA RESILIÊNCIA
}

\author{
COPING STRATEGIES USED BY PEOPLE WITH DISABILITY AND THE
}

IMPORTANCE OF A SUPPORT NETWORK IN STRENGTHENING RESILIENCE

Risonete Rodrigues da SILVA ${ }^{1}$

Rayssa Feitosa Feliz SANTOS ${ }^{2}$

Ana Lúcia LEAL ${ }^{3}$

\begin{abstract}
Resumo: este trabalho tem por finalidade proporcionar uma reflexão acerca da superação que muitas pessoas com deficiência alcançam diante das suas limitações. Partimos do pressuposto de que ao receber o diagnóstico, o paciente e sua família sentem um impacto emocional e social. Elegemos como objetivo geral compreender como algumas pessoas, com deficiências de tipos diferentes, lidam com suas limitações. Participaram deste estudo, duas pessoas com deficiência física, com 42 e 36 anos, duas com cegueira, 16 e 51 anos, e duas surdas, 34 e 27 anos. Este trabalho tem uma abordagem qualitativa e para coleta de dados utilizamos um questionário com questões abertas onde os participantes puderam formular livremente suas respostas. A partir dos resultados, concluímos que os participantes demonstraram, na maioria das vezes, atitudes condizentes a uma postura fortemente resilientes e que sempre houve pessoas e instituições que os apoiaram, inclusive professores passaram a ser seus tutores de resiliência de alguns deles.
\end{abstract}

Palavras-chaves: Resiliência. Educação Emocional. Pessoa com Deficiência.

Abstract: this work aims to provide a reflexion about overcoming that many people with disabilities reach in the face of their limitations. We start from the assumption that when receiving the diagnosis, the patient and his family feel emotional and social impact. We choose as a general objective to understand how some people, with various types of disability, deal with their limitations. Participated in this study two people with physically disability, with 42 and 36 years old, two with blindness, 16 and 51 years old, and two deaf, with 34 and 27 years old. This work has a qualitative approach and for data collection we use a quiz with open questions where the participants could to formulate their answers. From the results, we concluded that participants demonstrated, mostly, attitudes consistent with a strongly resilient posture and that there were always people and institutions who supported them, including many teachers became resilient guardians of some of them.

Keywords: Resilience. Emotional Education. People with Disability.

\footnotetext{
${ }^{1}$ Universidade Federal de Pernambuco - Centro Acadêmico do Agreste - UFPE/CAA. E-mail: risoneteprof@gmail.com

${ }^{2}$ UFPE/CAA. E-mail: rayyssa.felix@gmail.com

${ }^{3}$ UFPE/CAA. E-mail: analealchaves@yahoo.com.br
} 


\section{Introdução}

Este trabalho é parte das atividades avaliativas do mestrado, da disciplina Formação Humana e Educação Emocional, do programa de pós-graduação em Educação, em Ciências e Matemática da Universidade Federal de Pernambuco - Centro Acadêmico do Agreste UFPE/CAA. A nossa trajetória acadêmica e profissional está pautada na Educação Inclusiva de Pessoas com Deficiências e o contato com obras de autores como Cyrulnik e Viktor Frankl nos levou à ideia de realizarmos este trabalho.

Pois, na profissão que desempenhamos como professora de salas de Atendimento Educacional Especializado - AEE e intérprete de Libras - Língua Brasileira de Sinais, não é raro ver pessoas resilientes, mesmo diante de suas limitações causadas por síndromes que os tornaram cadeirantes, cegos ou surdos. Boris Cyrulnik (2004, p. 4), se refere à resiliência como a "capacidade de retomar o próprio desenvolvimento psíquico após traumas que estilhaçaram o seu universo sensorial e simbólico".

Muitos são os momentos na vida do ser humano que poderão proporcionar dificuldades e traumas de diferentes graus e dimensões, alguns mais leves e simples, outros mais complexos e duradouros. A partir do contato com os estudos dos autores acima citados, surgiu a seguinte inquietação: como uma pessoa que nasce "normal" e depois adquire alguma deficiência supera as dificuldades ou limitações que esta deficiência vem proporcionar para toda sua vida? Partimos do pressuposto que ao receber o diagnóstico, o paciente e sua família sentem o impacto emocional e social que a deficiência poderá gerar, principalmente no paciente e seus pais.

Para contemplar a nossa inquietação elencamos como objetivo geral: compreender como algumas pessoas, com vários tipos de deficiências, lidavam com suas limitações. E específicos: verificar possíveis impactos que o ser humano pode sentir ao ser diagnosticado (a) pessoa com deficiência, isto é, cega, surda ou cadeirante; identificar a existência de possível tutoria que fortalecesse a resiliência da pessoa com deficiência; analisar a importância da educação emocional no desenvolvimento profissional e social da pessoa com deficiência.

Este estudo tem por finalidade possibilitar uma reflexão acerca da superação que muitas pessoas com deficiência desenvolvem diante das suas limitações, pois nossa experiência aponta que muitas delas têm se mostrado fortemente resilientes diante de traumas e sequelas adquiridas 


\section{HORIZONTES - REVISTA DE EDUCAÇÃO}

e-ISSN: 2318-1540

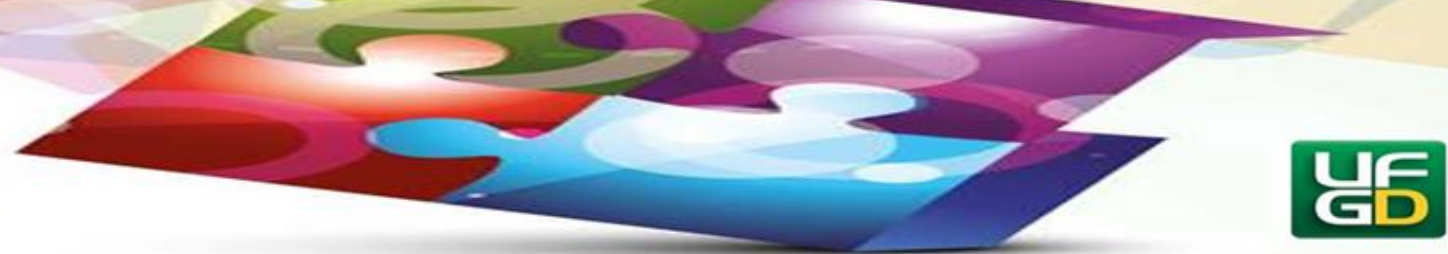

em sua vida. Pela pertinência da temática, buscaremos apresentar, a seguir, o significado da resiliência e como se entrelaça na temática da Educação Emocional.

\section{Resiliência e Educação Emocional}

Cyrulnik (2004) aprofundou seus estudos sobre a resiliência que, aplicado às ciências humanas, representa a capacidade do ser humano retomar o desenvolvimento psíquico depois de passar por traumas que despedaçam seu universo sensorial e simbólico. O termo resiliência, anteriormente utilizado na Física, denomina a capacidade que determinados materiais apresentam de voltar à forma anterior, depois de ter passado por algum tipo de deformação.

No campo das ciências humanas, onde nos deteremos, a resiliência não considera que o sujeito volta ao que era antes da exposição ao trauma, mas que consegue superar a situação adversa, se transformando. Poletto (2007, p. 17), afirma que "o sujeito aprende, cresce, se desenvolve e amadurece", ou seja, há uma transformação que torna o indivíduo melhor que antes, através desse processo transformador que é a resiliência.

Havia inicialmente a compreensão do conceito de resiliência como traço, que acreditava que era uma característica inata e permanente de alguns indivíduos. Assim, haveria pessoas que seriam consideradas não resilientes. Um conjunto de atributos das pessoas consideradas resilientes foi apresentado por Flach (1991, p. 124):

[...] um forte e flexível sentido de autoestima; independência de pensamento e ação, sem medo de depender dos outros ou relutância em ficar nessa condição de dependência; a habilidade de dar e receber nas relações com os outros, e um bem estabelecido círculo de amigos pessoais, que inclua um ou mais amigos que servem de confidentes; um alto grau de disciplina pessoal e um sentido de responsabilidade; reconhecimento e desenvolvimento de seus próprios talentos; mente aberta e receptiva a novas ideias; disposição para sonhar; grande variedade de interesses; apurado senso de humor; percepção de seus próprios sentimentos e do sentimento dos outros, e capacidade de comunicar esses sentimentos de forma adequada; grande tolerância ao sofrimento; concentração, um compromisso com a vida, e um contexto filosófico no qual as experiências pessoais possam ser interpretadas com significado e esperança, até mesmo nos momentos mais desalentadores da vida. 


\section{HORIZONTES - REVISTA DE EDUCAÇÃO}

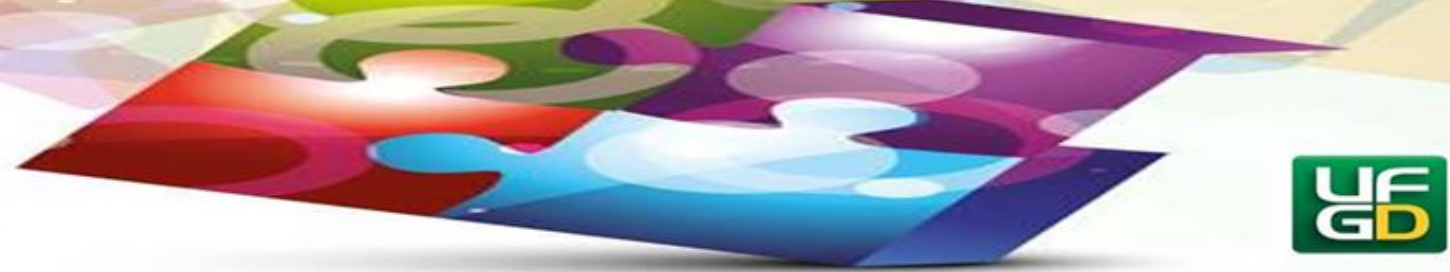

Nota-se que o foco do autor está nos atributos de ordem pessoal, estando mais relacionados ao fator individual do que ao relacional. Dessa forma, a resiliência podia ser compreendida como traço de alguns indivíduos.

Com o avanço das pesquisas, a resiliência passou a ser estudada também como um processo que se constrói a partir da interação entre a pessoa e o meio. Dessa forma, segundo Assis, Pesce e Avanci (2006), a resiliência pode ser vista como uma possibilidade para qualquer indivíduo.

A capacidade de voltar ao desenvolvimento psíquico não se apresenta apenas uma vez, mas essa necessidade de retomar se repete por toda a vida, pois cada nova dificuldade exige um novo enfrentamento, e isso se acontece nos diversos aspectos da vida humana. Nesta direção, Junqueira e Deslandes (2003, p. 229), afirmam que "não podemos falar de indivíduos resilientes, mas de uma capacidade do sujeito de, em determinados momentos e de acordo com as circunstâncias, lidar com a adversidade, não sucumbindo a ela". Assim, o processo de desenvolvimento de resiliência depende das interações e situações que quase sempre são imprevisíveis.

Murata (2013) destaca três categorias de fatores de proteção: Apoios e recursos externos relacionados ao meio ambiente, como o bom relacionamento com os amigos e professore; fatores pessoais ou individuais e os fatores familiares. O cuidado e o afeto dos familiares são essenciais para o desenvolvimento pessoal, profissional e para a qualidade das interrelações do sujeito, podendo se constituir como fatores de proteção e favorecedor de condutas resilientes.

Os fatores individuais de proteção incluem um conjunto de características que permitem a superação de situações adversas, dentre elas as quais destacam-se a capacidade de comunicação e de tomada de decisões; auto controle e flexibilidade (MURATA, 2013, p. 28).

O ambiente familiar estável e favorável, baixo nível de discórdia parental, relação positiva com irmãos são fatores de proteção. Mas, uma família com alto nível de discórdia, a falta de comunicação entre pais e filhos passa a ser fator de risco, assim como o baixo nível socioeconômico e cultural. Essas situações podem refletir no contexto escolar como fatores de risco, podendo ser observadas na falta de atenção nas aulas, agressividade, isolamento, entre outras. 


\section{HORIZONTES - REVISTA DE EDUCAÇÃO}

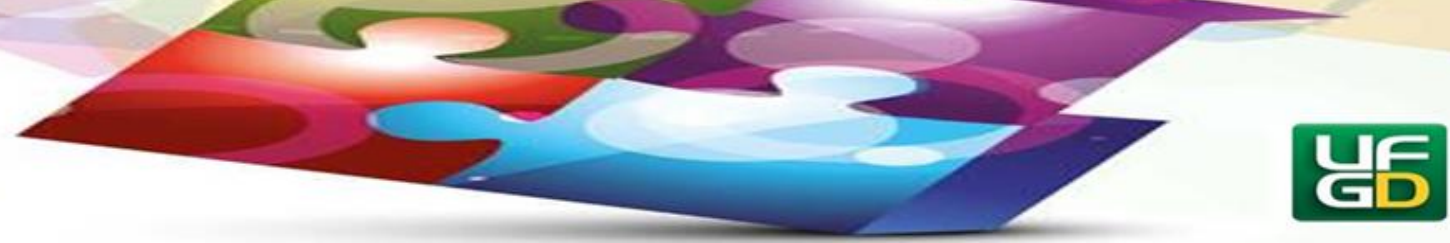

Segundo Murata (2013, p. 22), "o enfrentamento de situações adversas exige aquisição de novas competências para superar riscos, dar continuidade ao processo de desenvolvimento ou promover a capacidade de resiliência”. Assim, a família, a escola, o ambiente social é fundamental para que o sujeito crie vínculos e sentidos que contribuirá de forma significativa como fatores de proteção.

Portanto, "a interação entre fatores de risco e entre os fatores de proteção originam as redes de proteção. O processo de resiliência surge entre os mecanismos de risco e as redes de proteção, em presença de adversidades" (Idem, p. 27).

Nessas interações, entram em cena algumas pessoas que participam diretamente, apoiando e motivando para a superação, que são os chamados tutores de resiliência. Os tutores são pessoas próximas que se interessam pelo outro e tentam ajudá-lo, não o isentando de enfrentar o problema, mas, ao contrário, dando o suporte necessário para que este enfrente a situação de dificuldade com sucesso.

Para que ocorram mudanças bem-sucedidas é de suma importância que a pessoa tenha educação emocional, pois, diante da deficiência, pode desenvolver habilidades que instiguem novas maneiras de agir e conviver com a nova realidade, com suas limitações.

A educação emocional busca tornar um indivíduo mais inteligente emocionalmente. $\mathrm{O}$ que significa que ele terá mais chances de um convívio social estável. Além disso, será capaz de trabalhar em grupo, terá mais confiança diante dos desafios do dia-a-dia, estará mais apto ao relacionamento interpessoal e, principalmente, será mais otimista e equilibrado diante das exigências impostas pela sociedade (WEDDERHOFF, 2001, p. 5).

Consideramos, portanto, a Educação Emocional como um processo de desenvolvimento de habilidades de relacionamento interpessoal e intrapessoal. Nesta mesma direção, Condorelli, Guimarães e Azevedo (2010 p. 10) destacam que "a construção da nossa resiliência ou do nosso desmoronamento psíquico é um processo que se gesta ao longo de toda a nossa existência”. As instituições escolares, e de reabilitação, representam lugares onde as pessoas com deficiência podem vencer e superar os desafios.

Vencer desafios é uma tarefa que inspira a confiança da chance e abertura de possibilidades de driblar, ultrapassar, quebrar, vencer e superar barreiras e dificuldades encontradas na trajetória da vida pessoal e profissional (CASTRO, 2008 apud FARJADO, 2015, p. 127). 


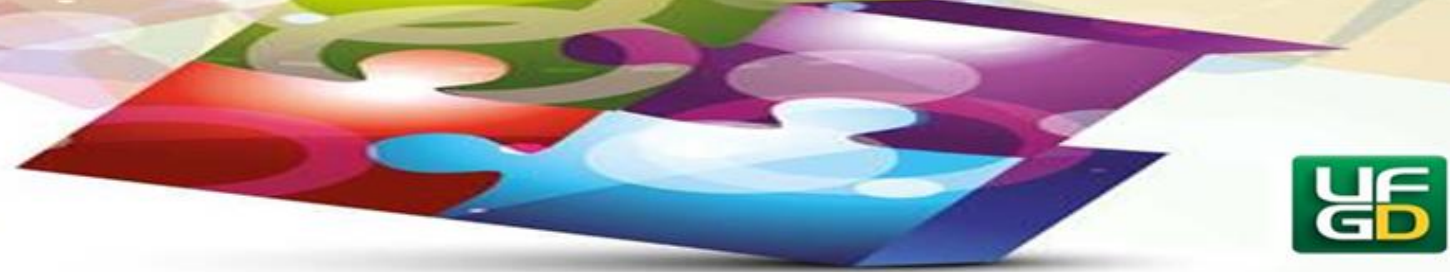

A instituição escolar, como também os centros de apoio à pessoa com deficiência, são espaços que proporcionam confiança e contribuem para a inclusão, já que além de ambientes de convivência são espaços de construção de conhecimentos. Como afirma Carvalho (2010, p. 159), espera-se que no ambiente escolar "prevaleça o propósito de oferecer a todos igualdade de oportunidades educacionais, o que não significa, necessariamente, que as oportunidades sejam as mesmas e idênticas, para todos”. Mas nem sempre a proposta foi a inclusão educacional, por isso, apresentaremos, a seguir, uma breve abordagem histórica da inclusão e/ou exclusão educacional de pessoa com deficiência.

\section{A in(ex)clusão da pessoa com deficiência em diferentes períodos da história}

O percurso histórico das pessoas com deficiências, quer sejam físicas, sensoriais ou cognitivas, não foi marcado por um movimento contínuo durante toda história. A maneira como a sociedade enxergava as pessoas com deficiência variavam de um país para outro, inclusive, em um mesmo período.

De acordo com Silva (1987), na Grécia Antiga, especificamente em Esparta, as crianças com deficiências eram lançadas de um penhasco. Essa atitude era devido à cidade-estado ter como marca principal o militarismo e crianças com alguma limitação não tinham utilidade para o exército espartano. Como também, guerreiros amputados, devido às batalhas conseguiam viver em Esparta. Na Roma antiga,

[...] cegos, surdos, deficientes mentais, deficientes físicos e outros tipos de pessoas nascidos com má formação eram também, de quando em quando, ligados a casas comerciais, tavernas e bordéis; bem como a atividades dos circos romanos, para serviços simples e às vezes humilhantes (Idem, p. 130).

Na obra "A epopeia ignorada: A pessoa deficiente na história do mundo de ontem e de hoje", Silva (1987) ressalta que na idade média, no período da Inquisição, nos séculos XI e XII, a Igreja Católica, adotou comportamentos discriminatórios e de perseguição à pessoa com deficiência, alegando que as limitações ou deformações eram castigos divinos. Assim, as pessoas com deficiência viviam em um contexto de exclusão, inclusive pela própria família, vivenciando pobreza e marginalidade, tendo que mendigar para poder sobreviver. 


\section{HORIZONTES - REVISTA DE EDUCAÇÃO}

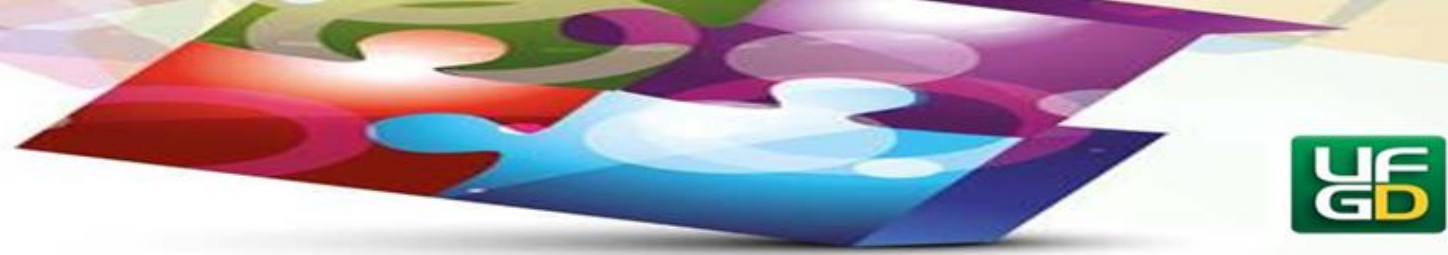

Entre os séculos XV e XVII, no mundo europeu cristão, começou um olhar diferenciado para a pessoa com deficiência, devido ao avanço da ciência, a libertação quanto a dogmas e crendices típicas da Idade Média, havendo assim, o reconhecimento do valor humano. Para Silva (1987, p. 226), isto

[...] alteraria a vida do homem menos privilegiado também, ou seja, a imensa legião de pobres, dos enfermos, enfim, dos marginalizados. E dentre eles, sempre e sem sombra de dúvidas, os portadores de problemas físicos, sensoriais ou mentais.

Desta forma, ao longo dos séculos e de forma tímida, foram sendo construídos locais de atendimento específico para pessoas com deficiência e as mesmas iam ganhando espaço na sociedade, podendo viver em sociedade como os demais cidadãos. Porém, esta luta persiste, pois, mesmo havendo leis e decretos que garantam a inclusão das pessoas com deficiência, na escola, no trabalho e no lazer ainda não há a efetivação desses direitos conquistados.

Adotada e proclamada pela Assembleia Geral das Nações Unidas, em 10 de dezembro 1948, a Declaração Universal dos Direitos Humanos Considera que o reconhecimento da dignidade inerente a todos os membros da família humana e de seus direitos iguais e inalienáveis é o fundamento da liberdade, da justiça e da paz no mundo. E que o desprezo e o desrespeito pelos direitos humanos resultaram em atos bárbaros que ultrajaram a consciência da humanidade.

Outro marco histórico é a Declaração de Salamanca, realizada em 1999, que trata Sobre Princípios, Políticas e Práticas na Área das Necessidades Educativas Especiais. O presente documento, em seus artigos 7 e 8 , afirma que o:

[...] princípio fundamental da escola inclusiva é o de que todas as crianças devem aprender juntas, sempre que possível, independentemente de quaisquer dificuldades ou diferenças que elas possam ter. [...] Educação inclusiva é o modo mais eficaz para construção de solidariedade entre crianças com necessidades educacionais especiais e seus colegas (UNESCO, 1996, art. 7 e $8)$.

Um a um os direitos das pessoas com deficiência passam a ser reconhecidos e legitimados. Em nosso país também são elaborados dispositivos legais para reconhecer e garantir os direitos desses cidadãos. No Brasil, a partir da Constituição Federal Brasileira de 1988, tornou-se direito o acesso e a permanência na escola. Desde então, outras leis, 


\section{HORIZONTES - REVISTA DE EDUCAÇÃO}

e-ISSN: 2318-1540

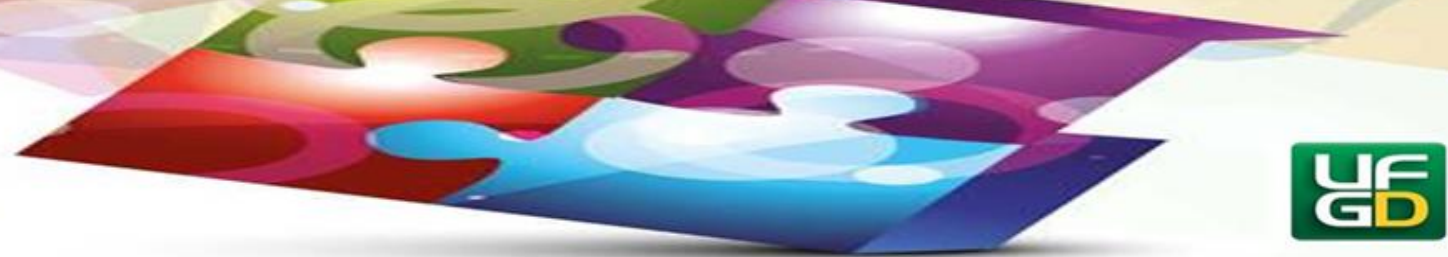

documentos e movimentos vem reafirmando que a educação é para todos. Entre eles podemos destacar a Conferência Mundial sobre Educação para Todos, que ocorreu em 1990, na Tailândia, afirmando que a escola deveria adaptar-se para garantir a igualdade de acesso à educação das pessoas com deficiência.

Em 1994 é publicada a Política Nacional de Educação Especial, orientando o processo de "integração instrucional" que condiciona o acesso às classes comuns do ensino regular àqueles que "[...] possuem condições de acompanhar e desenvolver as atividades curriculares programadas do ensino comum, no mesmo ritmo que os estudantes ditos normais" (p. 19).

Ao reafirmar os pressupostos construídos a partir de padrões homogêneos de participação e aprendizagem, a Política de 1994 não provoca uma reformulação das práticas educacionais de maneira que sejam valorizados os diferentes potenciais de aprendizagem no ensino comum, mas mantém a responsabilidade da educação desses estudantes exclusivamente no âmbito da educação especial.

Nesta perspectiva, a Lei de Diretrizes e Bases da Educação (Lei n.9394/96), o Estatuto da Criança e do Adolescente, a Política Nacional de Educação Especial, também defendem o direito à educação para todos. Mas deve haver cuidado com a compreensão desse direito. Rodrigues (2003, p. 15) afirma que “o ideal de 'escola para todos' [...] não pode ser entendido como redutor de "todos na escola".

Neste sentido, cabe aos sistemas de ensino, ao organizar a educação especial na perspectiva da educação inclusiva, disponibilizar as funções de instrutor, tradutor/intérprete de Libras e guia-intérprete, bem como de monitor ou cuidador dos estudantes com necessidade de apoio nas atividades de higiene, alimentação, locomoção, entre outras, que exijam auxílio constante no cotidiano escolar. Portanto, a escola inclusiva não se resume em colocar todos na escola, mas providenciar o que for necessário para suprir as necessidades educacionais de todos os estudantes.

No intuito de contemplar os objetivos elencados para este estudo, na sessão a seguir, iremos tratar a respeito da metodologia utilizada.

\section{Percurso metodológico}




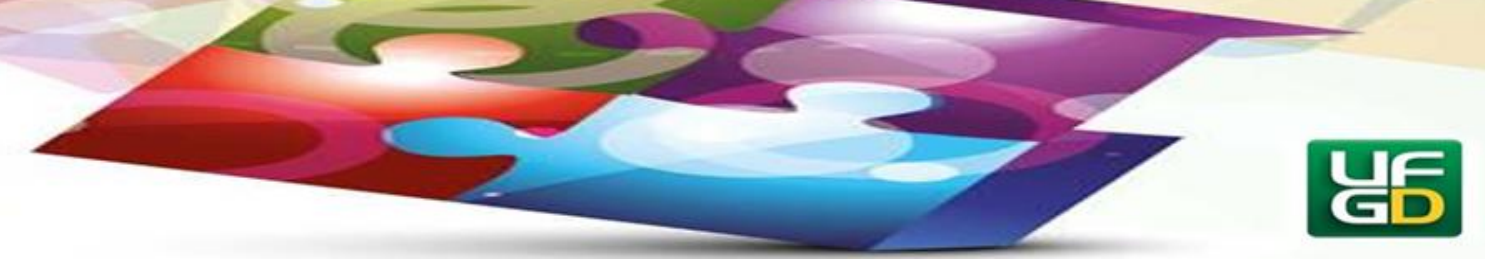

Este estudo tem uma abordagem qualitativa que, segundo Oliveira (2014, p. 37) implica em um

[...] processo de reflexões e análises da realidade através da utilização de métodos e técnicas para compreensão detalhada do objeto de estudo em seu contexto histórico e/ou segundo sua estruturação.

Para coletas de dados foi utilizado um questionário dotado de questões abertas. "A vantagem das questões abertas está no fato de o informante ter total liberdade para formular suas respostas" (OLIVEIRA 2014, p. 84). O questionário foi composto por quatro perguntas e aplicado a seis pessoas, sendo duas cegas, duas cadeirantes e duas pessoas surdas.

O único critério de inclusão utilizado foi que os participantes deveriam ser pessoas com deficiências. Devido à profissão desempenhada, como docentes de salas de Atendimento Educacional Especializado - AEE e intérprete de Libras - Língua Brasileira de Sinais, tivemos o nosso acesso facilitado aos participantes.

A professora de Braille, que leciona na mesma escola que trabalhamos, mediou o acesso às pessoas cegas e o questionário utilizado com as mesmas foi realizado na $\mathrm{ACACE}^{4}-$ Associação Caruaruense de Cegos. $\mathrm{O}$ acesso às pessoas com deficiências físicas foi facilitado por um estudante da UFPE, que é cadeirante, proporcionando o nosso contato com as pessoas que participam da APODEC ${ }^{5}$ - Associação de Pessoas com Deficiência Física de Caruaru. O acesso às pessoas Surdas foi mediado por um docente surdo, também da UFPE. Assim foram realizados os questionários com as pessoas surdas, no Centro Acadêmico do Agreste.

\section{Resultados e discussões}

A seguir, iremos apresentar alguns recortes das entrevistas realizadas com os participantes de nossa pesquisa e faremos a discussão alinhando com o que alguns autores tratam a respeito.

\footnotetext{
${ }^{4}$ Associação Caruaruense de Cegos tem por missão institucional, a promoção, a defesa e a garantia de direitos, a construção da autonomia, o fortalecimento do protagonismo, a inclusão e a emancipação social da pessoa cega e/ou com baixa visão. < http://www.acace.org.br/>

5 APODEC- Associação de Pessoas com Deficiência de Caruaru. Fundada em 13-11-1995, é uma entidade sem fins lucrativos e de utilidade Pública Municipal, que visa a integridade das pessoas com deficiência física na área de lazer, esportes, mercado de trabalho e na integração do convívio social. < http://apodeccaruaru.sitepx.com/historico-da-apodec.html>
} 


\section{HORIZONTES - REVISTA DE EDUCAÇÃO}

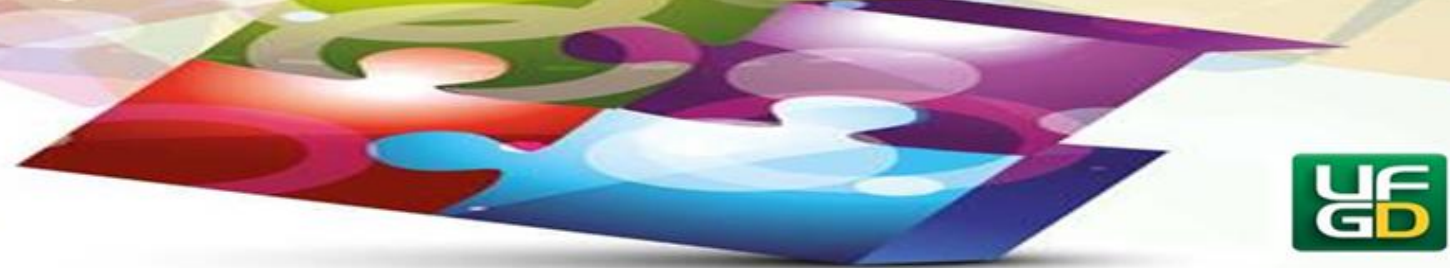

Nas respostas obtidas podemos observar a importância da educação escolar para que os participantes pudessem continuar normalmente com suas vidas. Apesar de não termos feito nenhuma pergunta específica sobre a educação escolar, eles mencionaram o estudo como forma de superação dos traumas vivenciados. Foi observado que a APODEC e a ACACE parecem funcionar como fatores de proteção e de fortalecimento da resiliência dos participantes, devido ao tipo de envolvimento que estes têm com essas Associações. Acreditamos que através destes vínculos é possível às pessoas com deficiência poderem estudar e terem sentimentos de pertença.

O participante 1, fala: "eu trabalho, fiz curso, estou bem". O participante 2, expressa: "sou universitário [...] tenho conhecimento dos meus direitos como pessoa com deficiência, como cidadão". O participante 3, diz: "nunca é tarde para estudar, [...] comecei a aprender Braille, hoje eu já escrevo". Os demais participantes não falaram a respeito dos estudos, mas dois são estudantes do ensino médio e um é docente de universidade. Assim, supomos que encontraram na educação oportunidades de enfrentamento das barreiras existentes, tão comuns no cotidiano das pessoas com deficiência.

A lei $\mathrm{n}^{\mathrm{o}} 13.146 / 2015$ no art. 27 destaca que

[...] A educação constitui direito da pessoa com deficiência, assegurados sistema educacional inclusivo em todos os níveis e aprendizagem ao longo de toda a vida, de forma a alcançar o máximo de desenvolvimento possível de seus talentos e habilidades físicas, sensoriais, intelectuais e sociais (BRASIL, 2015).

Entretanto, mesmo com avanços e conquistas na lei citada, que assegura educação de qualidade à pessoa com deficiência colocando-a a salvo de toda forma de violência, negligência e discriminação, não é raro observarmos esses direitos sendo negados a esse público. Apesar disto, os participantes da pesquisa não mencionaram violação aos seus direitos.

Para Cyrulnik (2009, p. 183), “cada história de vida é uma aventura humana única”. Isso fica claro ao observarmos as respostas dos dois surdos, quando questionados sobre qual reação apresentaram ao receberem o diagnóstico. O primeiro surdo comentou que compreendeu de forma natural, apenas aceitou; enquanto o segundo questionou o porquê disto acontecer com ele e foi tomado por um sentimento de raiva. É nesse sentido que Condorelli, Guimarães e Azevedo (2010, p. 4) afirmam que a resiliência "não é um processo linear, determinado de 


\section{HORIZONTES - REVISTA DE EDUCAÇÃO}

e-ISSN: 2318-1540

antemão a partir de certas causas que produzem sempre e necessariamente os mesmos efeitos". Uma determinada causa ou acontecimento na vida de uma pessoa, não garante que sua resiliência será fortalecida. Isso depende da postura adotada pelo indivíduo, frente às adversidades.

Para que haja um trauma é necessário um acontecimento marcante e significativo. Podemos perceber, nas respostas de alguns participantes, o quanto a realidade do diagnóstico foi impactante, mas o quanto é necessário entrar em contato com o sentimento, com as dores. Por exemplo, quando questionamos o participante 4, sobre sua reação ao se deparar com o diagnóstico, a resposta foi: "fiquei muito magoado, triste. Eu pensava que não tinha mais jeito, que o mundo ia se acabar ali. Pensei que não podia trabalhar e nem brincar mais com os meninos.” Nessa perspectiva, Cyrulnik $(2005$, p. 9) corrobora que:

Para experimentar um sentimento de acontecimento, é necessário que alguma coisa no real provoque uma surpresa e um significado que a tornem saliente. Sem surpresa, nada emergiria do real. Sem ser saliente, nada chegaria à consciência. Se um pedaço de realidade não "quisesse dizer nada", não se transformaria nem mesmo em uma lembrança. [...] quando um fato não se integra à nossa história porque não faz sentido, ele se apaga.

A maioria das respostas dos entrevistados segue a mesma direção, pois afirmam que experimentaram momentos de revolta, raiva, depressão, mágoa, desprezo, entre outros. Exceto no caso das pessoas surdas, os demais participantes nasceram "normais" e, posteriormente, tornaram-se pessoas com deficiências, mas parecem ter conseguido desenvolver a resiliência diante dos traumas físicos e psicológicos. Entendemos que a educação emocional é um fator determinante para que a pessoa desenvolva atitudes resilientes. Os participantes destes estudos compreenderam que não poderiam acabar com suas "deficiências", mas entenderam que poderiam conviver com suas limitações e, também, superá-las.

Quando questionado se já superou o diagnóstico, um participante surdo respondeu “consigo conviver, mas não superei completamente”. Segundo Cyrulnik (2004) apud Condorelli, Guimarães e Azevedo (2010 p. 18), “jamais conseguimos liquidar nossos problemas, sempre resta deles algum vestígio, mas podemos dar-lhes outra vida, mais suportável, com sentido" (grifo nosso).

Em relação ao sentido, Frankl (1991) acredita que o indivíduo precisa ter algo em função do que viver. Em seu livro ele mostra que mesmo em situações adversas, podemos encontrar 


\section{HORIZONTES - REVISTA DE EDUCAÇÃO}

um sentido para a vida. E, mais que isso, afirma que apesar das situações, muitas vezes trágicas, pelas quais passamos, se o ser humano tiver um sentido pelo qual viver, terá mais chances de superar as adversidades. Além da busca do sentido, que é o tema central de sua obra, Frankl também apresenta a Logoterapia, que tem a tarefa de auxiliar o paciente a encontrar sentido em sua vida. Dentre várias contribuições, trata sobre a Tese do Otimismo Trágico, nos levando a refletir como é possível optar pela vida e buscar o sentido para ser feliz, mesmo em diante das situações adversas que a vida impõe.

Percebemos nas respostas dos entrevistados que houve uma busca por sentido e alguns demonstram que o encontraram na crença em Deus. Com exceção do participante surdo mencionado anteriormente, os demais responderam que já superaram a notícia desse diagnóstico. Inclusive um entrevistado afirmou que "essa pergunta é a melhor, bênção. Já superei, glórias a Jesus. Porque eu encontrei paz, encontrei felicidade. Isso agora não me incomoda mais, porque agora eu sou feliz ao lado do Senhor Jesus Cristo". Uma informação que se repetiu por vezes nas respostas foi a crença na ajuda de um Transcendente.

A confiança em Deus, portanto, foi relatada por quase todos os entrevistados. Como vimos, Viktor Frankl (1991) explica que a esperança em algo ou alguém é uma forma de conseguir ver além do que se consegue no momento e, agindo dessa forma, a pessoa apresenta mais condições de passar pelas dificuldades, do que se a que não tiver encontrado um sentido pelo qual lutar. Neste caso, a religião foi fundamental para que os entrevistados, mesmo de crenças diferentes, encontrassem força e sentindo para continuarem lutando por suas vidas.

Cyrulnik (2005, apud CONDORELLI; GUIMARÃES; AZEVEDO, 2010, p. 9) critica todas as ideias que pretendem reduzir o homem a uma única das suas dimensões, pois é no entrelaçamento de fatores bioquímicos, psíquicos, sociais, culturais, etc., que se produzem o trauma e a resiliência. Quando a resiliência é instigada, os seres humanos transformam seus sofrimentos em um meio de luta para superar os entraves que a vida proporciona, tornando-se seres humanos melhores.

Em relação à última pergunta, que questionava se alguém ajudou ou está ajudando a superar os desafios dessa nova vida, todos os entrevistados, inclusive o que falou que ainda não superou completamente seus traumas, relataram que houve uma ou mais pessoas que os apoiaram e/ou apoiam nesse processo. Mencionaram os pais, o professor e as instituições de apoio, por encontrarem seus pares, havendo, assim, sentimento de pertença a um novo grupo 


\section{HORIZONTES - REVISTA DE EDUCAÇÃO}

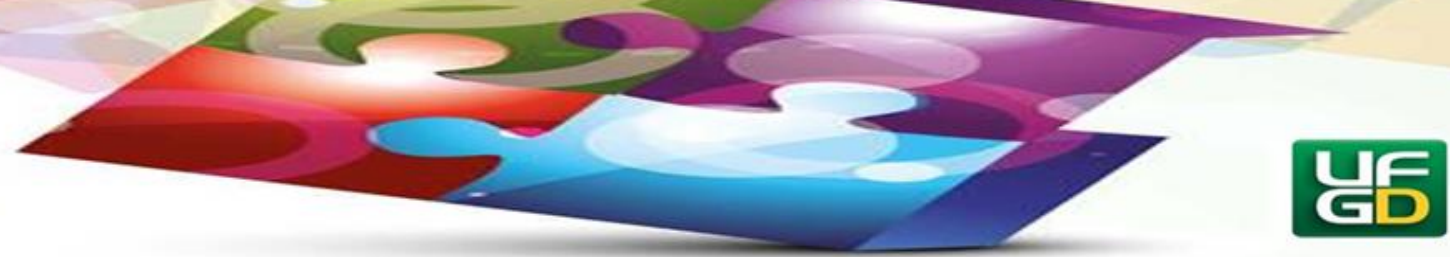

de pessoas que havia passado por traumas semelhantes. Nesta direção, Cyrulnik (2005, apud CONDORELLI; GUIMARÃES; AZEVEDO, 2010, p. 16) pontua que "o menor gesto que veicule a mensagem você existe para mim e me importo com o que você faz" contribui para que se estabeleçam relações cheias de significado e emoções, de forma a proporcionar transformações na maneira com que a pessoa enxerga a si mesmo, à sua própria história; levando a refletir sob como agir diante da tal situação em que se encontram. As pessoas que transmitem essa mensagem de apoio e valorizam sua existência são pessoas de grande importância no percurso para a superação das adversidades e, dependendo do grau de importância e influência que tenham, podem ser consideradas como tutores de resiliência.

\section{Considerações finais}

Este estudo revelou que a educação emocional é um fator determinante para o processo de desenvolvimento de atitudes resilientes. Os participantes deste estudo revelaram que não podem mudar suas condições, mas podem viver com suas limitações, superando as barreiras e entraves que a deficiência proporciona.

Também observamos que a possibilidade de estudarem e frequentarem as associações para pessoas com deficiência pareceram agir como fatores de proteção. Notamos que através da educação, os mesmos acreditaram ser possível adquirir conhecimentos relevantes que fortalecessem a militância dos movimentos pela efetivação das leis que poderão garantir os seus direitos. Já as associações denotam grande importância para as pessoas entrevistadas, devido ao apoio que oferecem para o enfrentamento às adversidades causadas pelas limitações impostas.

Desejávamos saber, como já mencionado, como algumas pessoas, tipos de deficiências diversas, lidavam com suas limitações e, ao término do presente trabalho, podemos apontar que os pais, a fé e os centros de apoio, foram fundamentais para que viessem a superar possíveis traumas psicológicos e/ou físicos. Também foram identificados os possíveis tutores de resiliência que contribuíram para que tivessem suas resiliências fortalecidas e pudessem amadurecer a partir do enfrentamento de suas dores. Ou seja, os participantes expressaram os apoios que receberam e quanto isso foi fundamental à superação de suas dores, com consequências diretas no fortalecimento de suas resiliências. 


\section{HORIZONTES - REVISTA DE EDUCAÇÃO}

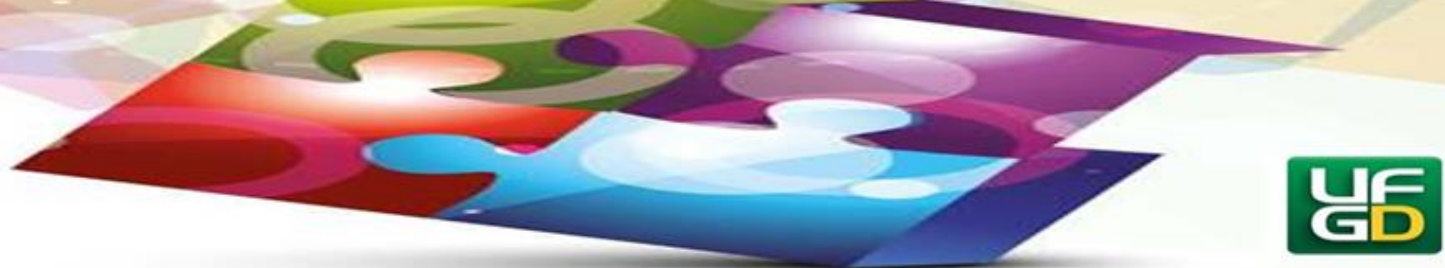

Verificamos, também, os possíveis impactos que poderiam ter sentido ao serem diagnosticados como deficientes e constatamos o quanto é importante o apoio de pessoas e/ou instituições, em momentos delicados, como no diagnóstico.

Destacamos, enfim, que em nosso estudo a resiliência dos participantes pareceu ter sido potencializada a partir do apoio recebido, tendo ele contribuído de forma significativa para o enfrentamento, superação e crescimento diante dos desafios que a pessoa com deficiência encontra pelo caminho, sendo o diagnóstico um momento delicado, essencial à aceitação e superação do sofrimento.

\section{Referências}

ASSIS, S. G.; PESCE, R. P.; AVANCI, J. Q. Resiliência: enfatizando a proteção na adolescência. Porto Alegre: Artmed, 2006.

BRASIL. Constituição (1988) Constituição Federal da República Federativa do Brasil. Brasília, DF, 1988.

. Declaração Mundial de Educação para todos, Conferência de Jomtien, 1990.

. Ministério da Educação. Lei de Diretrizes e Bases da Educação Nacional - LDB 9.394, de 20 de dezembro de 1996.

Secretaria de Educação Especial. Política Nacional de Educação Especial. Livro I/MEC/SEESP. Brasília, 1994.

Estatuto da pessoa com deficiência - Brasília: Senado Federal, Coordenação de Edições Técnicas, 2015. 65 p. Conteúdo: Lei no 13.146/2015.

CARVALHO, R. E. Educação Inclusiva: com os pingos nos "is". Porto Alegre, Mediação, 2010.

CONDORELLI, A.; GUIMARÃES, C. F.; AZEVEDO, C. R. S. O papel do educador como tutor de resiliência à luz das ideias de Boris Cyrulnik. Polyphonía, v. 21/1, jan./jun. 2010.

CYRULNIK, B. Os patinhos feios. São Paulo: Martins Fontes: 2004.

De corpo e alma. São Paulo: Martins Fontes, 2009.

FAJARDO, I. N. Resiliência e educação: exemplo das escolas do amanhã. 1. ed. Curitiba, Appris, 2015. 


\section{HORIZONTES - REVISTA DE EDUCAÇÃO}

e-ISSN: 2318-1540

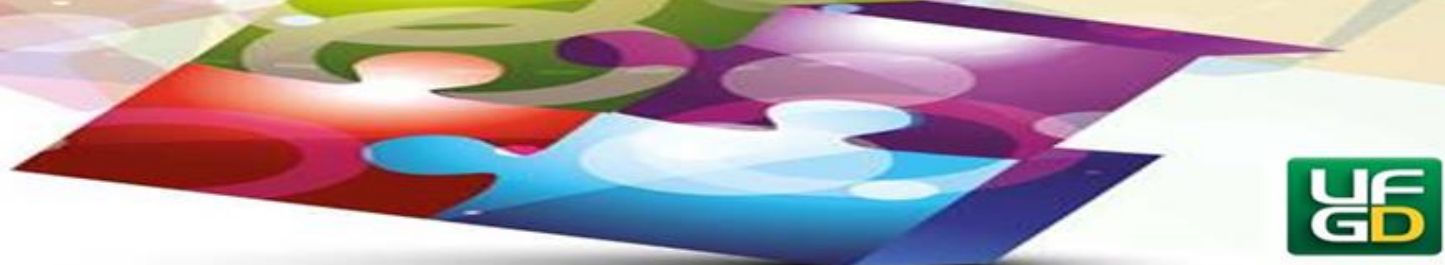

FLACH, F. Resiliência: a arte de ser flexível. São Paulo: Saraiva, 1991.

FRANKL, V.E. Em busca de sentido: um psicólogo no campo de concentração. Petrópolis, Vozes, 1991.

JUNQUEIRA, M. F. P. S.; DESLANDES, S. F. Resiliência e maus-tratos à criança. Cadernos de Saúde Pública, Rio de Janeiro, v. 19, n.1, 2003.

MURATA, M. P. F. Vulnerabilidade e Resiliência: fatores de risco e proteção em escolares com necessidades educativas especiais. São Carlos: UFSCar, 2013. Tese (Doutorado), Universidade Federal de São Carlos, 2013.

OLIVEIRA, M. M. Como fazer pesquisa qualitativa. 6. ed. - Petrópolis, RJ: Vozes, 2014.

POLETTO, M. Contextos ecológicos de promoção de resiliência para crianças e adolescentes em situação de vulnerabilidade. Dissertação (Mestrado em Psicologia) Programa de Pós Graduação em Psicologia do Desenvolvimento, Universidade Federal do Rio Grande do Sul, Porto Alegre, 2007.

RODRIGUES, A. J. Contextos de aprendizagem e integração/inclusão de alunos com necessidades educativas especiais. In RIBEIRO, M. L. S.; BAUMEL, R.C.R.C. Educação Especial: do querer ao fazer. São Paulo, Avercamp, 2003.

SILVA, O. M. Epopéia Ignorada: a História da Pessoa Deficiente no Mundo de Ontem e de Hoje. São Paulo: Cedas, 1987.

UNESCO. Declaração de Salamanca. Sobre Princípios, Políticas e Práticas na Área das Necessidades Educativas Especiais. 1996. Disponível em:

<http://portal.mec.gov.br/seesp/arquivos/pdf/salamanca.pdf> Acesso em: 17 jul. 2017.

WEDDERHOFF, E. Educação emocional: Um novo paradigma pedagógico? Revista Linhas e-ISSN 1984-7238 Qualis B2 v. 2, n. 1 (2001).

< http://www.periodicos.udesc.br/index.php/linhas/article/viewFile/1299/1110> Acesso em 14 jul. 2018.

Enviado:19/07/2018.

Aceito: 17/03/2019. 